\title{
CARACTERÍSTICAS TECNOLÓGICAS DE GENÓTIPOS DE TRIGO (Triticum aestivum L.) CULTIVADOS NO CERRADO
}

\author{
Technological characteristics of wheat (Triticum aestivum L.) genotypes grown in the \\ brazilian Cerrado
}

\author{
Luiz Carlos Gutkoski ${ }^{1}$, Bruna Klein², Fernanda Arnhold Pagnussatt ${ }^{2}$, Ivone Pedó $^{3}$
}

\begin{abstract}
RESUMO
Realizou-se este estudo com o objetivo de estudar as características grau de extração, proteína bruta, número de queda, alveografia, farinografia, volume específico e escore de pontos dos pães obtidos de amostras de grãos de genótipos de trigo (Triticum aestivum L.) plantados no cerrado brasileiro. Amostras de grãos de trigo dos genótipos Embrapa 22, Embrapa 42, Önix, Taurum e Fundacep 27, plantados no cerrado brasileiro, safra 2003/2004 foram avaliadas em delineamento inteiramente casualizado, no laboratório de Cereais do Centro de Pesquisa em Alimentação da Universidade de Passo Fundo, sendo os resultados experimentais analisados pelo emprego da análise de variância (Anova) e nos modelos significativos as médias comparadas entre si pelo teste de Tukey a 5\% de probabilidade de erro. As cultivares de trigo foram classificadas com base na alveografia e número de queda em melhorador, pão e brando. Nos trigos classificados como melhoradores as propriedades funcionais dos pães foram inferiores, o que define a utilização destas farinhas para mesclas com trigos de menor força de glúten. No cerrado brasileiro é possível produzir trigo classe melhorador.
\end{abstract}

Termos para indexação: Triticum aestivum, alveografia, farinografia, propriedades funcionais.

\begin{abstract}
The aim of this study was to investigate the characteristics of flour extraction grade, protein content, falling number, alveography, farinography, specific volume and point score of bread made from samples of grain of wheat genotypes grown in the Brazilian Cerrado. Samples of wheat grains of genotypes Embrapa 22, Embrapa 42, Önix, Taurum and Fundacep 27, grown in the Brazilian Cerrado, 2003/2004 crop, were disposed in fully randomized design, in the Cereal Laboratory at the Centro de Pesquisa em Alimentação of the University of Passo Fundo. The results were analyzed by variance analysis and the means compared by Tukey's test at 5\% error probability. The wheat cultivars were classified according to alveography and falling number in improved, bread and bland. In the wheat cultivars classified as improved the results of the bread's functional properties were lower, which defines the use of flour from improvement wheat for blending with wheat with smaller gluten power. It is possible to grow improved wheat in the Brazilian Cerrado.
\end{abstract}

Index terms: Triticum aestivum, alveography, farinography, functional properties.

(Recebido em 10 de março de 2006 e aprovado em 9 de agosto de 2006)

\section{INTRODUÇÃO}

O cerrado brasileiro se apresenta como uma alternativa para a produção de grãos de trigo (Triticum aestivum L.) em cultivo de sequeiro ou irrigado, pois é a primeira região a ser colhida no Brasil, o que pode garantir ao produtor melhor renda (SILVA, 2001). Instituições de pesquisa têm desenvolvido genótipos de trigo adaptados à região e que apresentem elevadas produtividades. É necessário buscar novas tecnologias de cultivo, de sistema de produção e a caracterização destes genótipos, visando a utilização em produtos de panificação (BRAZ \& BRAGA, 1997).
A qualidade do grão de trigo pode ser definida como resultado da interação que a cultura sofre no campo, as condições do solo, clima, incidência de pragas e moléstias, manejo da cultura, cultivar, bem como das operações de colheita, secagem, armazenamento, moagem e das características genéticas (POMERANZ, 1987). No Brasil existem cultivares de trigo adaptadas e com alta força de glúten, as quais são denominadas de melhoradores (BRASIL, 2001). As avaliações físicas, reológicas e funcionais de trigos são de vital importância para a indústria de panificação, pois permite definir a proporção a ser utilizada nas mesclas de trigos e de farinhas (RAO \& RAO, 1993).

'Engenheiro Agrônomo, Dr. Professor Titular III, Faculdade de Agronomia e Medicina Veterinária da Universidade de Passo Fundo/UPF - Cx. P. 611 99001-970 - Passo Fundo, RS - Bolsista produtividade CNPq - gutkoski@upf.br

${ }^{2}$ Aluna do curso de Engenharia de Alimentos da Universidade de Passo Fundo/UPF - Cx. P. 611 - 99001-970 - Passo Fundo, RS - Bolsista de iniciação científica PIBIC/UPF e BIC/CNPq - aealimentos@upf.br; nandapagnu@terra.com.br

${ }^{3}$ Nutricionista, MSc. Professora Adjunto do Instituto de Ciências Biológicas da Universidade de Passo Fundo/UPF - Cx. P. 611 - $99001-970$ - Passo Fundo, RS - pedo@upf.br 
Dada a grande diversidade de farinhas de trigo é necessária a utilização de vários métodos para determinar essas características. Os métodos mais utilizados são os relacionados com as características reológicas da massa, a partir de sistemas simples de mistura de água e farinha. Existe uma série de aparelhos para medir estas propriedades, tais como farinógrafo, extensógrafo e alveógrafo. A definição de uso final de uma farinha deve ser feita após a avaliação conjunta destes resultados (CALDEIRA et al., 2003). Os valores de peso do hectolitro, número de queda, força geral do glúten, tempo de mistura, estabilidade da massa, micotoxinas, grãos danificados e resíduos de agrotóxicos são usados para estabelecer o ágio ou deságio do trigo produzido e permitem que o mercado ofereça produtos com características perfeitamente identificáveis. Incluem-se nestes, trigos para usos como os diferentes tipos de pães, produção de biscoitos, produção de massas alimentícias e até mesmo para ração (BACALTCHUK, 1999).

Com o presente trabalho, objetivou-se estudar as características peso do hectolitro, número de queda, grau de extração, proteína bruta, alveografia, farinografia, volume específico e escore de pontos dos pães de amostras de grãos de genótipos de trigo plantados no cerrado brasileiro.

\section{MATERIAL E MÉTODOS}

Amostras de $15 \mathrm{~kg}$ de grãos de trigo dos genótipos Embrapa 22, Embrapa 42, Ônix, Taurum e Fundacep 27, plantados no cerrado brasileiro, safra 2003/2004 pela OR Melhoramento de Sementes foram submetidos à limpeza em separador de impurezas modelo Sintel e às análises realizadas em delineamento inteiramente casualizado no laboratório de Cereais do Centro de Pesquisa em Alimentação da Universidade de Passo Fundo.

Peso do hectolitro. Determinado de acordo com Regras de Análise de Sementes (BRASIL, 1992), pelo uso de balança marca Dalle Molle e os resultados expressos em kg.hL ${ }^{-1}$.

Peso de mil grãos. Determinado de acordo com a metodologia descrita por Regras de Análise de Sementes (BRASIL, 1992) através da contagem manual de cinqüenta grãos em quadruplicata e os resultados expressos em gramas.

Moagem experimental. Realizada em moinho piloto marca Chopin, de acordo com o método número 26-10 da AACC (1999), através de uma passagem pelo sistema de quebra e duas passagens pelo sistema de redução. Foram determinados a porcentagem de farinha de quebra e extração de farinha, realizado em duplicata.
Número de queda. Determinado em farinha de trigo através do uso do aparelho Falling Number, marca Perten Instruments, de acordo com o método 56-81B da AACC (1999), utilizando sete gramas de amostra, corrigido para $14 \%$ de umidade e realizado em triplicata.

Proteína bruta. Determinada em espectrômetro do infravermelho próximo, marca Perstorp Analytical e utilizado a curva de calibração fartam construída pelo laboratório de Físico-Química do Cepa a partir do método Kjeldahl (AACC, 1999), em triplicata.

Alveografia. As características viscoelásticas da farinha de trigo foram determinadas no alveógrafo marca Chopin, modelo NG (Villeneuve-la-Garenne Cedex, França) utilizando o método $\mathrm{n}^{\circ}$ 54-30 da AACC (1999), através da pesagem de 250 gramas de farinha e volume de $129,4 \mathrm{~mL}$ de água, corrigido na base de $14 \%$ de umidade. Os parâmetros obtidos nos alveogramas são tenacidade (P), que mede a sobrepressão máxima exercida na expansão da massa $(\mathrm{mm})$; extensibilidade (L), que mede o comprimento da curva (mm) e energia de deformação da massa (W), que corresponde ao trabalho mecânico necessário para expandir a bolha até a ruptura, expressa em $10^{-4} \mathrm{~J}$.

Farinografia. As características da massa durante a mistura foram determinadas no Promilógrafo marca Max Egger, modelo T6 (Blasen, Áustria), pelo uso de $100 \mathrm{~g}$ de farinha de trigo e realizadas de acordo com as recomendações do manual do aparelho (PROMYLOGRAPH, 2001). Os parâmetros avaliados foram absorção de água, que indica a qualidade da farinha refletida pela capacidade de intumescimento do glúten e o teor de amido danificado; tempo de desenvolvimento, que corresponde ao intervalo decorrente desde a primeira adição de água até o ponto de máxima consistência (pico); estabilidade, definida como a diferença de tempo entre o ponto em que o topo da curva intercepta a linha média de 500 UP e o ponto da curva que deixa a linha.

Panificação experimental. O preparo da massa foi realizado de acordo com o método $\mathrm{n}^{\circ} 10-80 \mathrm{~B}$ da AACC (1999), com adaptações, sendo utilizado farinha (100\%), gordura vegetal hidrogenada $(3 \%)$, sal refinado $(1,75 \%)$, ácido ascórbico $(0,01 \%)$, açúcar $(5 \%)$, fermento biológico (3\%) e água a $4^{\circ} \mathrm{C}$, adicionada de acordo com a absorção no promilógrafo.

Os ingredientes foram misturados na misturadora marca Kitchen Aid, modelo K5SSWH2, na velocidade média por sete minutos. Adicionou-se o fermento biológico e misturou-se por mais seis minutos. A massa foi retirada da misturadora, dividida em porções de 175 $\mathrm{g}$, sendo estas colocadas em formas de tamanho padrão, 
e deixada em descanso por dez minutos. Na operação de fermentação, as massas foram colocadas em câmara marca Multipão, regulada na temperatura de $30 \pm 1^{\circ} \mathrm{C}$ e umidade relativa de $80 \%$. O monitoramento foi realizado pelo uso de termo-higrógrafo. O cozimento foi realizado no forno, marca Labor Instruments, modelo QA 226, regulado na temperatura de $220{ }^{\circ} \mathrm{C}$ por 18 minutos, e após os pães esfriarem por uma hora foram realizadas as análises.

Avaliação dos pães. O volume foi determinado pelo método de deslocamento de sementes de painço e o volume específico calculado pela relação entre o volume do pão assado e o seu peso, obtido pelo emprego de balança semianalítica. A determinação do volume específico foi realizada uma hora após o cozimento dos pães, com três repetições e os resultados expressos em $\mathrm{cm}^{3} \mathrm{~g}^{-1}$. A avaliação do escore de pontos dos pães foi realizada por provadores treinados e utilizado a escala de pontos para as características cor da crosta, forma e simetria, características da crosta, aspectos de quebra da crosta, textura do miolo, cor do miolo, aroma e sabor, conferindo-lhes, a partir destes resultados, um valor (avaliação global) com pontuação máxima de 100, de acordo com a metodologia proposta por El-Dash (1978).

Análise estatística. A análise dos resultados foi realizada através do emprego da análise de variância (Anova) e nos modelos significativos as médias comparadas entre si pelo teste de Tukey a $5 \%$ de probabilidade de erro. O processamento de dados e a análise estatística foram realizados com o uso do programa estatístico SAS ${ }^{\circledR}$ (SAS INSTITUTE, 1985).

\section{RESULTADOS E DISCUSSÃO}

A Instrução Normativa SARC $n^{\circ} 7$ do Ministério da Agricultura, Pecuária e Abastecimento de 15 de agosto de 2001 (BRASIL, 2001) classifica o trigo em tipos 1, 2 e 3 de acordo com o peso do hectolitro, umidade, teor de matérias estranhas e impurezas e porcentagem de grãos avariados. $\mathrm{O}$ peso do hectolitro das amostras variou entre 79,45 e $83,55 \mathrm{~kg} \mathrm{hL}^{-1}$, sendo enquadrado todas as cultivares analisadas como tipo 1 (Tabela 1). A cultivar Ônix apresentou PH significativamente superior, seguido de Fundacep 27 e Taurum. O menor PH foi verificado na cultivar Embrapa 22. $\mathrm{O}$ peso de mil grãos (PMG) não variou significativamente entre as cultivares Fundacep 27, Embrapa 22, Embrapa 42 e Taurum, sendo significativamente inferior $(p \geq 0,05)$ na cultivar Ônix. O PMG é utilizado para classificar o trigo pelo tamanho, onde grãos de tamanho excessivo não são desejados pela indústria, pois podem provocar perdas devido às dificuldades de regulagem dos equipamentos de limpeza e moagem, enquanto grãos pequenos podem passar pelas peneiras de limpeza e causar perdas na produção de farinha pela diminuição da quantidade de trigo moído (GUARIENTI, 1996). A diferença de tamanho dos grãos também influencia na quantidade de água absorvida, onde grãos pequenos absorvem maior quantidade de água em relação aos grãos grandes durante a etapa de condicionamento (POSNER, 1990).

A extração de farinha variou entre $65,02 \%$ e $69,11 \%$, sendo o menor valor verificado na cultivar Taurum de característica dura e o maior valor na cultivar Embrapa 22 de característica semi-dura. A quantidade de farinha de quebra obtida na cultivar Fundacep 27 foi maior quando comparado com as demais cultivares estudadas. Este comportamento é explicado pela dureza do grão, sendo 'Fundacep 27' o único material com característica semi- mole. De acordo com Guarienti (1996), os trigos duros apresentam menores taxas de extração e de farinha de quebra, enquanto em trigos moles ou semi-moles são verificados maiores valores de extração e de farinha de quebra.

TABELA 1 - Peso do hectolitro (PH), peso de mil grãos (PMG), farinha de quebra e extração de farinha de amostras de grãos dos genótipos Fundacep 27, Embrapa 22, Embrapa 42, Ônix e Taurum cultivados no cerrado brasileiro, safra 2002/ 2003 pela OR Melhoramento de Sementes Ltda.

\begin{tabular}{|c|c|c|c|c|}
\hline Cultivar $^{1}$ & $\begin{array}{c}\mathbf{P H} \\
\left(\mathrm{kg} \mathrm{hL}^{-1}\right) \\
\end{array}$ & $\begin{array}{c}\text { PMG } \\
\text { (g) }\end{array}$ & $\begin{array}{c}\text { Farinha quebra } \\
(\%)\end{array}$ & $\begin{array}{c}\text { Extração } \\
(\%)\end{array}$ \\
\hline Fundacep 27 & $81,30 \mathrm{~b}$ & $45,45 \mathrm{a}$ & 37,15 & 66,60 \\
\hline Embrapa 22 & $79,45 \mathrm{~d}$ & $41,60 \mathrm{a}$ & 19,11 & 69,11 \\
\hline Embrapa 42 & $80,80 \mathrm{c}$ & $44,60 \mathrm{a}$ & 20,68 & 68,47 \\
\hline Ônix & 83,55 a & $35,80 \mathrm{~b}$ & 17,30 & 65,86 \\
\hline Taurum & $81,60 \mathrm{~b}$ & $45,30 \mathrm{a}$ & 16,25 & 65,02 \\
\hline
\end{tabular}

${ }^{1}$ Médias seguidas das mesmas letras na coluna não diferem estatisticamente pelo teste de Tukey a 5\% de probabilidade de erro.

Ciênc. agrotec., Lavras, v. 31, n. 3, p. 786-792, maio/jun., 2007 
O número de queda das farinhas apresentou valores de 338 a 500 segundos (Tabela 2), sendo a cultivar Fundacep 27 significativamente inferior e classificada como trigo de ótima atividade enzimática. As farinhas dos demais trigos estudados apresentaram valores maiores sendo classificados como de baixa atividade enzimática (PERTEN, 1967). O número de queda recomendado para elaboração de pão tipo forma é entre 300 e 350 segundos (FERREIRA et al., 1999) e é usado para avaliar a atividade da enzima aamilase de grãos e farinhas, a fim de detectar danos causados pela germinação na espiga. $\mathrm{O}$ excesso de aamilase causa problemas na produção de pão como descoloração da crosta, miolo seco e pequeno volume (PERTEN, 1967). Dimmock \& Gooding (2002) verificaram que o número de queda está negativamente associado com o teor de umidade e peso médio do grão.

Os teores de proteína bruta das farinhas variaram entre 15,11 e 17,95\%, valores expressos em base seca (Tabela 2), o que permite classificar como de qualidade muito alta e extra-alta (GUARIENTI, 1996). Nas cultivares Embrapa 42 e Ônix os teores de proteína bruta foram significativamente superiores ( $\mathrm{p} \leq 0,05)$, seguidos de 'Embrapa 22' e 'Fundacep $27^{\prime}$. A qualidade das proteínas está relacionada à capacidade de formação da massa, ou seja, quando são misturadas farinha de trigo e água, tem-se como resultado a formação de uma massa constituída pela rede protéica do glúten ligado aos grânulos de amido que retêm o gás formado e permite o aumento de volume (BUSHUK, 1985). O autor verificou correlação positiva entre o teor de proteínas do grão de trigo e o volume do pão produzido, o que implica em alta qualidade tecnológica destas proteínas.

A alveografia é um teste reológico usado em vários países para a determinação de características qualitativas da farinha através dos parâmetros força geral do glúten (W), relação elasticidade e extensibilidade $(\mathrm{P} / \mathrm{L})$ e índice de elasticidade (IE) (Tabela 2). A força geral do glúten (W) é a medida da área da curva do alveograma e permitiu classificar os trigos 'Embrapa 22', 'Embrapa 42' e 'Taurum' como melhoradores, 'Ônix' como trigo pão e 'Fundacep 27 ' como trigo brando (BRASIL, 2001). Os trigos 'Embrapa 22' e 'Taurum' apresentaram maior elasticidade (P), enquanto os trigos 'Fundacep 27', 'Embrapa 22' e 'Ônix' se mostraram mais extensíveis. De acordo com a relação P/ L o trigo 'Fundacep 27' apresentou glúten extensível, 'Embrapa 22', 'Ônix' e 'Taurum' glúten balanceado e o trigo 'Embrapa 42' glúten tenaz.

O balanço preciso das propriedades viscoelásticas da massa é fator essencial para a determinação de uso final. A presença de glúten elástico é necessária tanto em farinhas de panificação, quanto de massas alimentícias, enquanto que um glúten menos elástico é requerido em farinhas para bolos e biscoitos (DOBRASZCZYK \& MORGENSTERN, 2003). A expressão força de glúten normalmente é utilizada para designar a maior ou menor capacidade de uma farinha sofrer um tratamento mecânico ao ser misturada com água. Também é associada à maior ou menor capacidade de absorção de água pelas proteínas formadoras de glúten, que combinadas à capacidade de retenção do gás carbônico resulta em um pão de volume aceitável, textura interna sedosa e de granulometria aberta (TIPPLES, 1982).

A farinografia é um dos mais completos e sensíveis testes para a avaliação da qualidade de mistura da massa de farinha de trigo. Alguns parâmetros determinados pela farinografia são absorção de água, tempo de chegada, tempo de desenvolvimento, tempo de saída e estabilidade

TABELA 2 - Número de queda, proteína bruta (base seca), força geral do glúten (W), relação elasticidade e extensibilidade (P/L) e índice de elasticidade (IE) de farinha de amostras de trigo dos genótipos Fundacep 27, Embrapa 22, Embrapa 42, Ônix e Taurum cultivados no cerrado brasileiro, safra 2002/2003 pela OR Melhoramento de Sementes Ltda.

\begin{tabular}{lccccc}
\hline Cultivar $^{\mathbf{1}}$ & $\begin{array}{c}\text { Número de } \\
\text { queda }(\mathbf{s})\end{array}$ & $\begin{array}{c}\text { Proteína } \\
\text { bruta }(\boldsymbol{\%})\end{array}$ & $\begin{array}{c}\mathbf{W} \\
\left(\mathbf{1 0}^{-\mathbf{4}} \mathbf{J}\right)\end{array}$ & $\mathbf{P} / \mathbf{L}$ & $\begin{array}{c}\text { IE } \\
(\boldsymbol{\%})\end{array}$ \\
\hline Fundacep 27 & $338 \mathrm{e}$ & $16,58 \mathrm{c}$ & 118 & 0,45 & 39,8 \\
Embrapa 22 & $500 \mathrm{a}$ & $17,61 \mathrm{~b}$ & 471 & 0,67 & 70,1 \\
Embrapa 42 & $455 \mathrm{~b}$ & $17,95 \mathrm{a}$ & 301 & 1,39 & 66,0 \\
Onix & $401 \mathrm{c}$ & $17,81 \mathrm{ab}$ & 267 & 0,67 & 66,7 \\
Taurum & $370 \mathrm{~d}$ & $15,11 \mathrm{~d}$ & 338 & 1,17 & 62,3 \\
\hline
\end{tabular}

${ }^{1}$ Médias seguidas das mesmas letras na coluna não diferem estatisticamente pelo teste de Tukey a 5\% de probabilidade de erro. 
(GUARIENTI, 1996). As avaliações de farinografia, com base no tempo de desenvolvimento e estabilidade, indicaram que a cultivar Embrapa 22 e Taurum podem ser classificadas como farinha muito forte. A cultivar Ônix apresentou farinha com característica classificada como forte (Tabela 3). Foi verificada uma relação entre estabilidade e força geral do glúten. Os maiores valores de estabilidade e W ocorreram nos trigos das cultivares Embrapa 22 e Taurum. A absorção de água variou entre 57,5\% e 60,5\% e é um indicativo da capacidade das farinhas em absorver água para a elaboração de pão (FELÍCIO et al., 1998).

Os pães de forma foram elaborados e avaliados conforme metodologia proposta por El-Dash (1978), utilizando farinha de trigo dos genótipos Fundacep 27, Embrapa 22, Embrapa 42, Ônix e Taurum cultivados no cerrado brasileiro. As características avaliadas foram volume específico, cor da crosta, quebra, simetria, crosta, cor do miolo, textura do miolo, aroma e sabor, obtendo o escore total de pontos (Tabela 4). Para volume específico, os pães elaborados com a farinha do genótipo Fundacep
27 foram significativamente superiores, apresentado 14,52 $\mathrm{cm}^{3} \mathrm{~g}^{-1}$, sendo que o máximo para esta determinação é de $20 \mathrm{~cm}^{3} \mathrm{~g}^{-1}$. Embora a farinha da cultivar Fundacep 27 seja a de menor força geral de glúten (Tabela 2), ela possibilitou a elaboração de pão com o maior volume quando comparado com os demais genótipos estudados. Isto ocorreu provavelmente devido ao excesso de força de glúten nos demais trigos avaliados, comprovando que são trigos melhoradores, devendo ser usados em mesclas com trigos de menor W. Para a produção de pão de forma o recomendado é a utilização de farinha com 180 a $240 \times 10^{-4}$ J (GUARIENTI, 1986).

De acordo com o escore total de pontos, os pães elaborados com farinha das cultivares Fundacep 27, Embrapa 22, Embrapa 42 e Ônix foram classificados como de boa qualidade, com valores acima de 81 e não diferindo significativamente entre si ( $p>0,05)$. Os pães elaborados com farinha da cultivar Taurum foram classificados como regulares com escore de pontos de 77,99, ficando abaixo dos 81 pontos preconizados por Ferreira (2002).

TABELA 3 - Determinações farinográficas de absorção de água, tempo de chegada (T.C.), tempo de desenvolvimento (T.D.), tempo de saída (T.S.) e estabilidade de farinha de amostras de trigo dos genótipos Fundacep 27, Embrapa 22, Embrapa 42, Ônix e Taurum cultivados no cerrado brasileiro, safra 2002/2003 pela OR Melhoramento de Sementes Ltda.

\begin{tabular}{lccrr}
\hline Cultivar & $\begin{array}{c}\text { Absorção de água } \\
(\mathbf{m L})\end{array}$ & $\begin{array}{c}\text { TC } \\
(\mathbf{m i n})\end{array}$ & $\begin{array}{c}\text { TD } \\
(\mathbf{m i n})\end{array}$ & $\begin{array}{c}\text { Estabilidade } \\
(\mathbf{m i n})\end{array}$ \\
\hline Fundacep 27 & 57,5 & 1,00 & 1,30 & 5,30 \\
Embrapa 22 & 59,5 & 7,30 & 22,00 & 24,30 \\
Embrapa 42 & 60,5 & 7,00 & 11,30 & 6,30 \\
Ônix & 59,7 & 6,30 & 9,30 & 10,30 \\
Taurum & 58,7 & 3,30 & 15,00 & 19,00 \\
\hline
\end{tabular}

TABELA 4 - Volume específico e escore de pontos do teste experimental de pão de forma da farinha de amostras de trigo dos genótipos Fundacep 27, Embrapa 22, Embrapa 42, Ônix e Taurum cultivados no cerrado brasileiro, safra 2002/ 2003 pela OR Melhoramento de Sementes Ltda.

\begin{tabular}{lcc}
\hline Cultivar $^{\mathbf{1}}$ & $\begin{array}{c}\text { Volume específico } \\
\left(\mathbf{c m}^{\mathbf{3}} \mathbf{g}^{\mathbf{- 1}}\right)\end{array}$ & $\begin{array}{c}\text { Escore de pontos } \\
\mathbf{( 0 ~ a ~ 1 0 0 )}\end{array}$ \\
\hline Fundacep 27 & $14,52 \mathrm{a}$ & $89,02 \mathrm{a}$ \\
Embrapa 22 & $12,41 \mathrm{bc}$ & $82,91 \mathrm{ab}$ \\
Embrapa 42 & $13,18 \mathrm{~b}$ & $88,15 \mathrm{ab}$ \\
Ônix & $12,28 \mathrm{c}$ & $83,77 \mathrm{ab}$ \\
Taurum & $11,99 \mathrm{c}$ & $77,99 \mathrm{~b}$ \\
\hline
\end{tabular}

${ }^{1}$ Médias seguidas das mesmas letras na coluna não diferem estatisticamente pelo teste de Tukey a 5\% de probabilidade de erro.

Ciênc. agrotec., Lavras, v. 31, n. 3, p. 786-792, maio/jun., 2007 


\section{CONCLUSÕES}

As cultivares de trigo foram classificadas com base nas análises de alveografia e número de queda em melhorador, pão e brando. Nos trigos classificados como melhoradores as propriedades funcionais dos pães foram inferiores, o que define a utilização destas farinhas para mesclas com trigos de menor força de glúten. No cerrado brasileiro é possível produzir trigo classe melhorador.

\section{AGRADECIMENTOS}

Os autores agradecem à Fundação de Amparo a Pesquisa do Estado do Rio Grande do Sul (Fapergs), pelo auxílio financeiro e a empresa OR Sementes pelo material experimental.

\section{REFERÊNCIAS BIBLIOGRÁFICAS}

AMERICAN ASSOCIATION OF CEREAL CHEMISTS Approved methods of the AACC. 8. ed. Saint Paul, 1999. Paginação irregular.

BACALTCHUK, B. Qualidade dos alimentos exigida pelos consumidores no século XXI. In: CONFERÊNCIA BRASILEIRADE PÓS-COLHEITA, 1., 1999, Porto Alegre. Anais... Passo Fundo: Abrapós/Cesa/Embrapa Trigo, 1999. v. 1, p. 13-22, 293 p.

BRAZ, A. J. B. P.; BRAGA, F. M. Avaliação de cultivares e linhagens do ensaio do centro brasileiro de trigo irrigado. In: REUNIÃO NACIONAL DE PESQUISA DE TRIGO, 18. 1997, Rio Verde. Anais... Passo Fundo: Embrapa Trigo, 1997.

BRASIL. Ministério da Agricultura, do Abastecimento e da Reforma Agrária. Secretaria Nacional de Defesa Agropecuária. Regras para análise de sementes. Brasília, DF, 1992. 365 p.

BRASIL. Ministério da Agricultura, Pecuária e Abastecimento. Instrução normativa SARC no 7, de 15 de agosto de 2001. Aprova o regulamento técnico de qualidade do trigo. Disponível em: 〈http//www.agricultura.gov.br $>$. Acesso em: 11 maio 2005.

BUSHUK, W. Flour proteins: structure and functionality in dough and bread. Cereal Foods World, Saint Paul, v. 30, n. 7, p. 447-451, 1985.

CALDEIRA, M. T. M.; LIMA, A. L. V.; SEKI, A. H.; RUMJANEK, D. F. Diversidade de trigos, tipificação de farinhas e genotipagem. Biotecnologia e Desenvolvimento, São Paulo, p. 44-48, 2003.

DIMMOCK, J. P. R. E.; GOODING, M. J. The effects of fungicides on Hagberg falling number and blackpoint in winter wheat. Crop Protection, Guildford, n. 21, p. 475-487, 2002.

DOBRASZCZYK, B. J.; MORGENSTERN, M. P. Rheology and the breadmaking process. Journal of Cereal Science, London, v. 38, p. 229-245, 2003.

EL-DASH, A. A. Standardized mixing and fermentation procedures for experiments baking test. Cereal Chemistry, Saint Paul, v. 55, n. 336, p. 436-446, 1978.

FELÍCIO, J. C.; CAMARGO, C. E. O.; GERMANI, R.; MOGNO, C. P. R. S. Interação entre genótipo e ambiente na produtividade e na qualidade tecnológica dos grãos de trigo no estado de São Paulo. Bragantia, Campinas, v. 57, n. 1, 1998.

FERREIRA, P. B. M.; WATANABE, E.; BENASSI, V. T. Estudo do processo de produção de pão francês préassado. Brazilian Journal of Food Technology, Campinas, v. 2, p. 91-95, 1999.

FERREIRA, S. M. R. Controle da qualidade em sistemas de alimentação coletiva I. São Paulo: Varela, 2002.

GUARIENTI, E. M. Qualidade industrial de trigo. Passo Fundo: Embrapa-CNPT, 1996. 36 p.

PERTEN, H. Factors influencing falling number values. Cereal Science Today, Saint Paul, v. 12, n. 12, p. 516-519, 1967.

POMERANZ, Y. Modern cereal science and technology. New York: VHC, 1987. 486 p.

POSNER, E. S. La influencia del tamano del grano de trigo sobre la aptitude molineria. In: SEMINARIO TECNICO-ECONOMICO DE MOLINERIA, 1990, Fortaleza. Anais... Fortaleza: U.S. Wheat Associates, 1990. p. 20-31.

PROMYLOGRAPH. Betriebsanleitung für den promylograph. Blasen: M. Egger Largeräte, 2001. Paginação irregular. 
RAO, G. V.; RAO, P. H. Methods for determining rheological characteristics of doughs: a critical evaluation. Journal of Science Technology, Peshawar, v. 30, n. 2, p. 77-87, 1993.

SAS INSTITUTE. User's guide: statistics. 5. ed. Cary, 1985. $965 \mathrm{p}$.
SILVA, M. S. e. Trigo no Brasil começa nos Cerrados. Anuário Brasileiro do Trigo, Passo Fundo, v. 1, 2001.

TIPPLES, K. H.; PRESTON, K. R.; KILBORN, R. H. Implications of the term "strength" as related to wheat and flour quality. Bakers Digest, Merrian, p. 16-20, 1982. 